\title{
Good Practices on Labour and Birth Care
}

\author{
Elisabete Mesquita Peres de Carvalho* \\ Fundação de Ensino e Pesquisa em Ciências da Saúde, Brasília, Brazil \\ *Corresponding author: Elisabete Mesquita, Fundação de Ensino e Pesquisa em Ciências da Saúde, Brasília, Brazil; Email: elisabete_mpc@yahoo.com.br
}

Received: May 14, 2021; Accepted: May 20, 2021; Published: May 27, 2021

The implementation of good care practices for normal childbirth and the reduction of unnecessary interventions, recommended by the World Health Organization since 1996, has been reinforced by the Brazilian Ministry of Health through successive public policies [1]. The literature, however, suggests that there are gaps in the understanding of the work process of professionals who work in childbirth care, and there is low adherence to practices based on scientific evidence by the group [2]. A few decades ago, when a woman would begin labour, she would start the so-called pilgrimage in search of a bed in maternity wards. When she would get a place, she would be admitted without the right of a companion. Conducting labour included fasting, enteroclysis, trichotomy, routine venous hydration, routine oxytocin, collective pre-delivery, lithotomy delivery, routine episiotomy, kristeller maneuver, among other practices without scientific evidence. The parturients did not question the medical or nursing conduct. They remained passive throughout labour and delivery, entrusting their bodies to the "protagonists of birth".

As it is an event that involves cultural processes, individual and social interactions, with different powers and legitimacy, the implementation of the new model develops with excessive delay. However, a lot has already been done, since this process is in full development and there is no turning back. Scientific evidence reveals that during labour and delivery it is extremely positive for the mother and the child the presence of a companion, the assessment of foetal well-being, the offer of liquids and a light diet, non-pharmacological pain relief, walking encouraged, freedom of position and movement, empathic support by service providers, the provision of information on the progress of labour or any guidance the parturient may require during this period $[3,4]$. Literature also suggests that good practices need to be disseminated and incorporated into the daily lives of all middle and senior professionals who permeate the birth scenario. However, if the proposal is to change the model with a theoretical and practical grounding of humanized obstetric care, orientation needs to take place since the training of these professionals, in order to compose the curriculum of the political-pedagogical project of the courses [5].

The existence of nursing residency programs has shown to be a particularly strong influence for changing the model, especially when the course is guided by the ideology of care centred on women, encouraging the use of good obstetric practices, reducing unnecessary interventions, the de-medicalization of health, the promotion of autonomy and women empowerment [5]. Bearing in mind that part of today's preceptors come from the old training model that they have received as student-residents and reproduce the biomedical and hospital-focused models, there is a clear need for greater investment in obstetric residency programs, as well as in the processes of care providers' work to promote a more innovative and less conservative approach to care [3]. Pedagogical practice is a process that is intrinsically linked to the articulation of theory and teaching practice, which is built and rebuilt in daily life and so it must be transformative and involve the multiple dimensions of the teaching-learning process, from teacher training, student profile, teaching methodology, learning objectives and curriculum, teaching strategies, educational assessment to the relationship between teacher and student [6]. In this context, it is suggested to strengthen actions that promote greater adherence to the best care practices, both in relation to the organization of labour and birth care, as well as the attitudes and values of health professionals, granting more in-depth training and qualification to care providers in order to improve care management using a holistic and evidencebased approach, centered on self-care, humanization, security, and human rights [3]. There are many challenges facing the proposal to change the model and include the training of new professionals, the qualification of the agents involved in training, and the organization of childbirth care services, in order to standardize and make use of good protocols and good clinical guidelines already published by the World Health Organization corroborating to the standardization of protocols, building trust among the team and assuring that everyone is guided by the same clinical precepts, regardless of where they were trained. The ongoing change in the labour and birth scenario is the result of countless collective processes that seek the implementation of well-conducted public policies, efforts by local administrators, change in the attitude of former workers in the face of new evidence, women's organized movements and, without a doubt, the qualification of the training of new professionals forged in the expertise of Good Obstetric Practices.

\section{References}

1. Gottems LBD, Carvalho EMP de, Guilhem D, Pires MRGM (2018) Boas práticas no parto normal: análise da confiabilidade de um instrumento pelo Alfa de Cronbach. Revista Latino-Americana de Enfermagem 26.

2. Carvalho EMP de, Göttems LBD, Pires MRGM (2015) Adherence to best care practices in normal birth: construction and validation of an instrument. Revista da Escola de Enfermagem da USP 49: 889-897.

3. Carvalho EMP de, Amorim FF, Santana, LA, Göttems LBD (2019) Avaliação das boas práticas de atenção ao parto por profissionais dos hospitais públicos do Distrito Federal, Brasil. Ciência \& Saúde Coletiva 24: 2135-2145. 
4. Leal MC, Bittencourt SA, Esteves-Pereira AP, Ayres BVS, Silva LBRAA, et al. (2019). Avanços na assistência ao parto no Brasil: resultados preliminares de dois estudos avaliativos. Cad Saúde Pública 35.

5. Carvalho EMP de, Göttems LB, Amorim FF, Guilhem DB (2020) The training of obstetric physicians and nurses to change the obstetric model in Brazil: A view of the preceptors in the training process. Journal of Nursing Education and Practice, 10 .

6. Fonseca NV, Carvalho EMP de, Göttems LBD (2020) A formação de técnicos de enfermagem para a promoção do cuidado à saúde da mulher. Comunicação em Ciências da Saúde.

\section{Citation:}

Peres de Carvalho EM (2021) Good Practices on Labour and Birth Care. Integr J Nurs Med Volume 2(1): 1-2. 